\title{
Research of Electro-mechanical Actuator in Electric Braking System Based on Instantaneous Torque Control with SRM
}

\author{
Gao Bing ${ }^{1, *}$ and Gao Jie ${ }^{2}$ \\ ${ }^{1}$ Engineering Technology Training Center, Civil Aviation University of China, Tianjin, 300300-China \\ ${ }^{2}$ Aeronautical Automation College, Civil Aviation University of China, Tianjin, 300300-China
}

\begin{abstract}
In order to improve the reliability and braking torque of aircraft electric braking system, this paper selected switched reluctance motor (SRM) as drive motor of electromechanical actuator, static torque data of SRM calculated by finite element analysis were used as training samples, then characteristics of torque-angle were obtained off-line by Generalized Regression Neural Network with particle swarm optimization (PSO-GRNN), and the nonlinear mapping from the torque to current was completed, torque inverse model is obtained which has large effects on the control performance of Instantaneous torque control, finally combining the torque sharing function (TSF) to constitute the torque control system of SRM. Simulation and experiment are proved: the system has good dynamic performance, and it can quickly and accurately track the expected braking torque.
\end{abstract}

Keywords: Electric Braking system, Switched Reluctance Motor (SRM), instantaneous torque control, PSO-GRNN.

\section{INTRODUCTION}

With multi-electric technology is widely used in the aircraft, the all-electric braking system has been widespread concern and research, this paper focus on the electromechanical actuator which is a core component for electric braking subsystem of more electric aircraft, while the motor as the actuating link of the entire system, its performance characteristics plays a key role in the ability to meet the technical specifications and achieve control strategy [1]. Aiming at high reliability, high efficiency requirement of electric braking system, the SRM is the preferred solution for actuator system, which has changed the traditional hydraulic actuator, with no hydraulic oil and hydraulic components such as hydraulic pipes, pumps and valves, and using the motor, drive mechanism and brake controller together to constitute the digital actuation system, so the comprehensive performance such as maintenance, reliability and braking efficiency are all superior to traditional hydraulic system. Meanwhile, compared with other motor selection for electro-mechanical actuator, the simply structure, low cost, and the absence of windings and permanent magnets on the rotor makes SRM a viable candidate for various general use. The phase independence characteristic of SRM makes it extremely fault tolerant for critical applications. Those unique features of the SRM make it ideally suitable for the aerospace $[2,3]$.

However, from the perspective of control, the drive system of SRM is nonlinear and time-varying, although compared to traditional AC and DC speed control system, SRM is simple, reliable and efficient, etc., but the torque of SRM is a nonlinear function of the stator current and rotor position angle, so as the power supply is the switching power, the torque ripple will be very serious [4]. Therefore, in order to improve the braking torque and efficiency, reducing torque ripple is very important for the brake actuator control.

Due to the detection means in SRM torque control are single, and the precision of constructed torque observer is limited, so it is more difficult to achieve closed-loop torque control. Currently torque ripple optimization method is divided into two categories: the first one is optimal design of the motor [5-7], while the other one is the application of advanced control strategies. In recent years, domestic and foreign experts have proposed a variety of torque control strategy [6-10]. As 8/6 SRM is concerned, two-phase excitation control strategy can effectively reduce starting torque ripple, but as speed increases, the mutual flux has greater impact on the torque, and the two-phase excitation strategy is difficult to reduce torque ripple during commutation [11]. In addition, some scholars have proposed the use of an ideal current distribution to get a smooth torque in order to achieve the purpose of suppressing the torque ripple, but due to the higher speed, the rate of change of current becomes greater, so it makes difficult to track the actual current for given current [12]. As the electromagnetic properties of SRM is highly nonlinear and strong coupling, even injecting constant current to the phase winding, the instantaneous torque generated will not be smooth. In recent years, simple direct instantaneous torque control (DITC) gradually attracted great attention and enthusiasm of industry experts and scholars, but this method is dependent on the sampling period, although the structure is simple, to achieve smooth torque output need relatively complex switching strategies [13]. In this paper, 


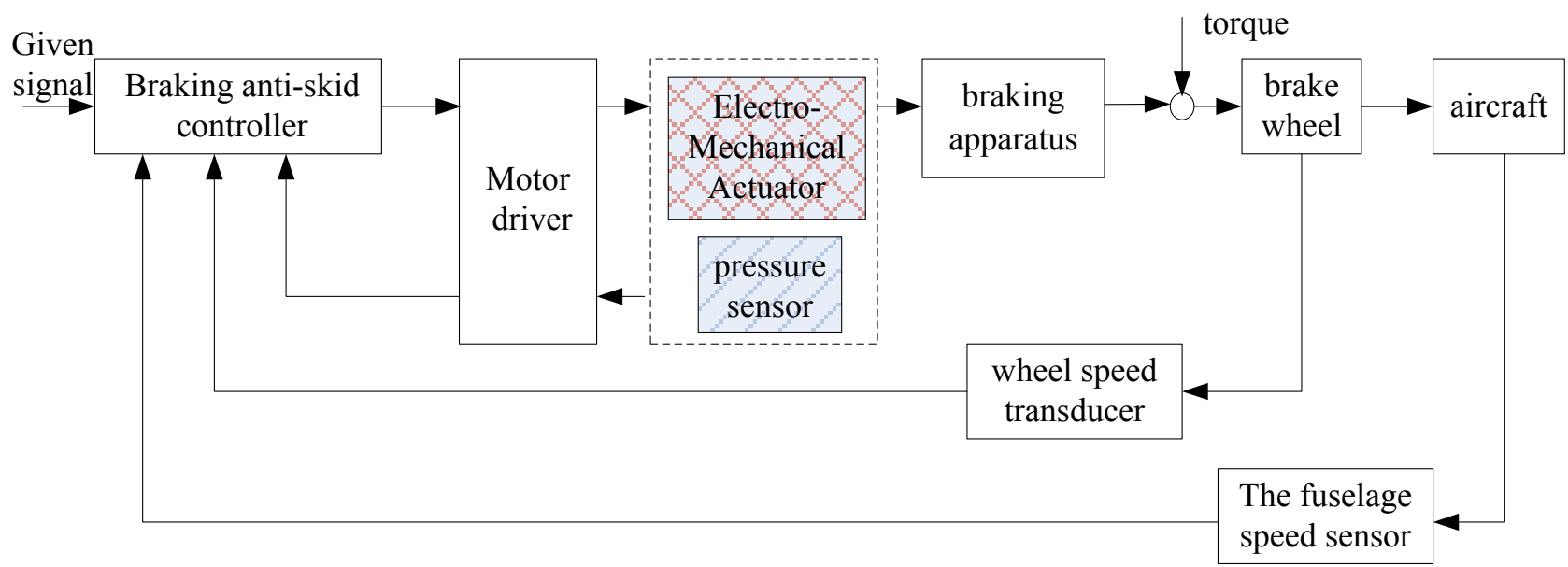

Fig. (1). The block diagram of all electrical braking system operation principle.

PSO-GRNN is used to offline train torque inverse model of SRM, combined with the torque distribution function and voltage PWM control to constitute SRM instantaneous torque control system, the torque can better track given.

\section{THE COMPOSITION AND PRINCIPLE OF ELEC- TRIC BRAKING SYSTEM}

As one group of electric braking system, it mainly has the following several parts: electromechanical actuator (EMA), EMA driver, the sensor of braking pressure, wheel speed braking frame, further EMA is composed of motor, reducer and ball screw mechanism. All electrical braking system operation principle block diagram is shown in Fig. (1), wheel speed signal directly into electrical anti-skid braking controller through speed sensor installation on the braking wheel. The signal of braking pressure is detected by the actuating pressure sensor which is integrated with EMA, and the signal is directly lead to the motor driver, then amplified for all electric anti-skid braking controller. According to the above two feedback signals, also with the desired braking torque signal and the corresponding given slip rate, the anti-skid controller will produce corresponding output braking force given signal as the input of motor driver, and the signal drive motor forward rotation and output torque, via the speed reducer drive the ball screw, applied the axial thrust to the brake disk, by the way of the dynamic, static friction between the braking disc, changing the brake torque, and finally braking aircraft. Those all compose of double negative feedback closed loop control system formed with the wheel speed and braking torque [14].

As shown in Fig. (1), the actuating element of the whole system is electromechanical actuators, the core component is SRM, which responses to the input of anti-skid controller, uses ball screw to make the rotation output converted into linear motion of SRM after reducer, and thus suppresses the motive wheel to brakes.

The SRM drives screw axial rotation under axial load, and the load torque of SRM is:

$$
\begin{aligned}
& T_{M}=J_{M} \dot{\omega}+T_{L} \\
& T_{L}=\left(T_{P L}+T_{D}+T_{f}\right) \frac{1}{i \eta} \\
& T_{D}=\frac{F L}{2 \pi \eta} \\
& T_{P L}=\frac{F_{p} L}{2 \pi \eta}\left(1-\eta^{2}\right)
\end{aligned}
$$

where, $\omega$ is the angular velocity of the feed screw, $J_{M}$ is the moment of inertia, $\eta$ and $i$ are respectively expressing the transmission efficiency and gear ratio between ball screw and gear pair of motor shaft, $T_{f}$ is the friction torque of ball screw drive system, $T_{D}$ is drive torque of the ball screw, $T_{P L}$ is the moment of resistance, $F$ is the axial load, $L$ is the screw thread pitch, $F_{p}$ is axial pre-tightening force.

The friction torque of ball screw refers to the friction moment of ball screw outside friction torque itself, and mainly refers to the friction torque support bearings and seal friction torque, its value is small, so we can give an estimate in the design.

The rotation of the motor pressure on the pressure disc by the transmission device, Accordance with the following formula:

$$
\frac{\omega t}{2 \pi}=\frac{x}{L}
$$

where, $x$ is the axial displacement of the screw. The angular velocity determines axial displacement, and the axial displacement is a linear relationship with the braking torque, therefore the motor torque of brake actuator directly determines braking torque.

\section{THE INSTANTANEOUS TORQUE CONTROL OF SRM}

The instantaneous torque control flow diagram based on PSO-GRNN is shown in Fig. (2), the system is proposed by controlling the phase winding current tracking expectations 


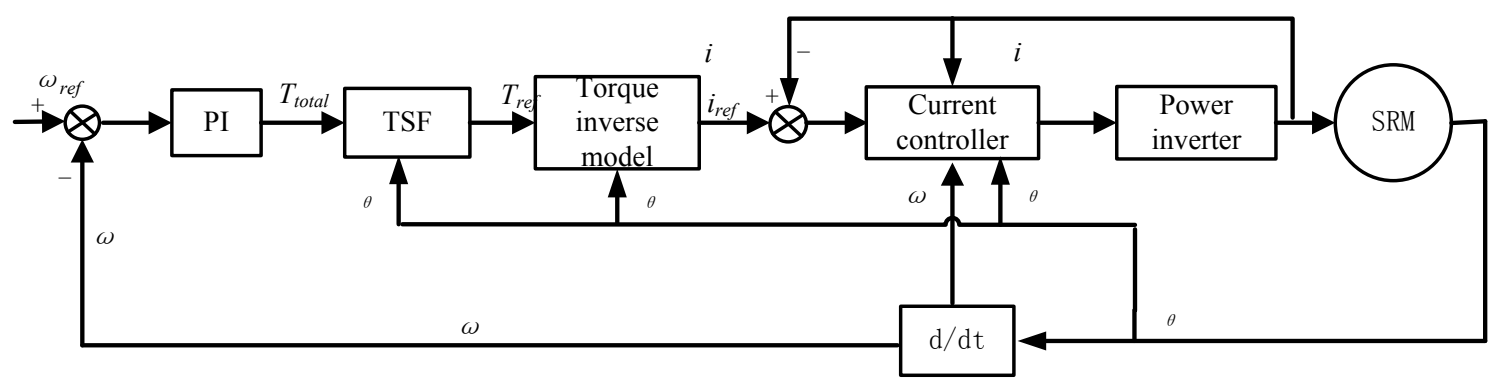

Fig. (2). The block diagram of all electrical braking system operation principle.

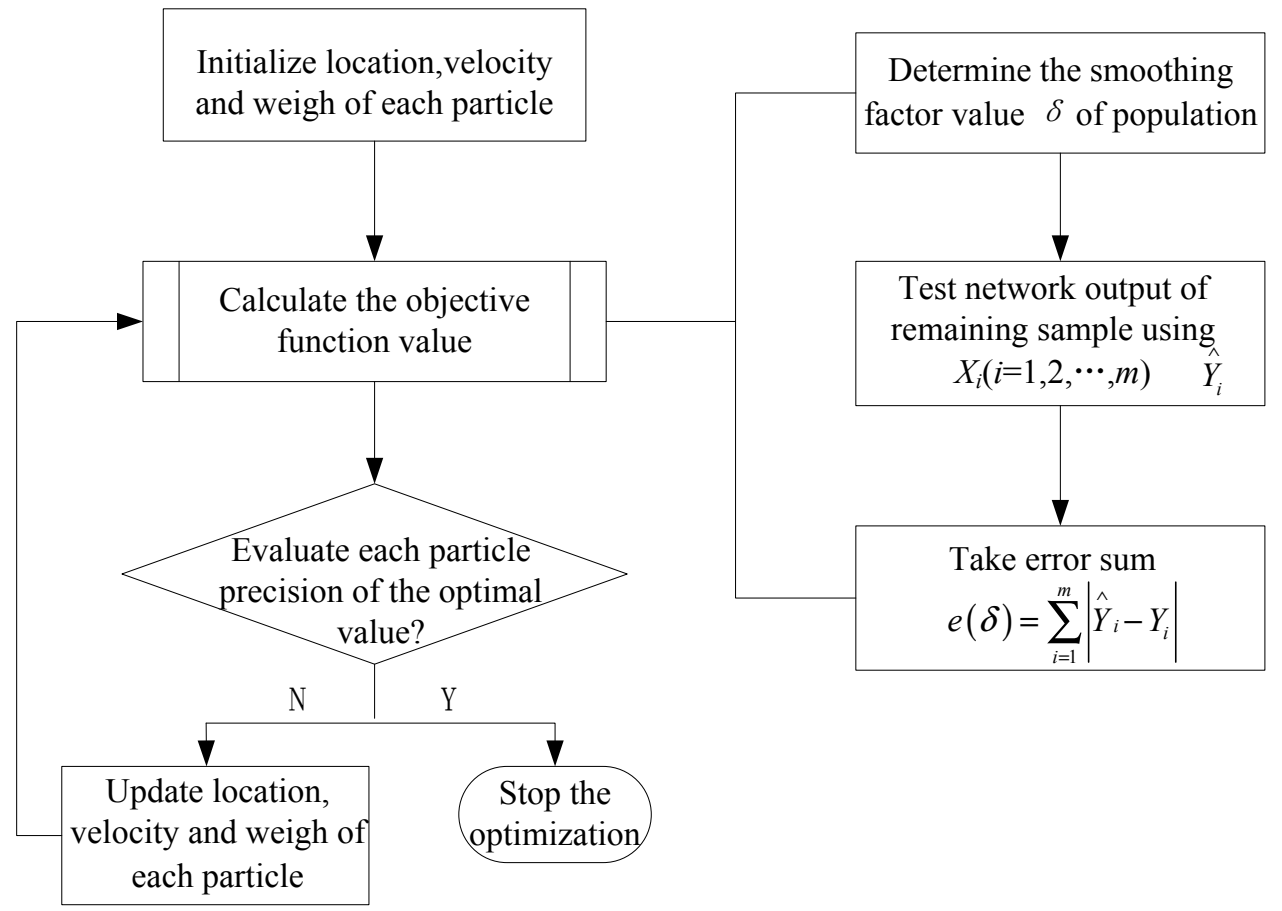

Fig. (3). The flow chart of GRNN optimized by PSO.

current value, in order to achieve the purpose of controlling the instantaneous torque. First the static torque inverse model of training and learning are implemented by PSO-GRNN algorithm, and then based on TSF to achieve a reasonable distribution of the torque of each phase, and finally phase current expectations calculation of the desired torque determined by torque inverse model. Since the torque is realized by controlling the phase current, the torque inverse model has relatively large impact on the control performance. Based on PSO-GRNN learning, this paper improves the accuracy of torque inverse model and meets the system requirements of real-time control.

\subsection{The Torque Inverse Model of SRM based on PSO- GRNN}

PSO is an optimization tool based on iterative theory, which is committed to simulate the interaction between individual behaviors. The method omits the tedious crossover and mutation operations in the traditional genetic algorithm, and gets the whole search space by the particle flight, PSO can significantly improve the convergence speed of GRNN, in addition the generalization ability of the network is the important index to measure the ability of learning and modeling accuracy, and the two indexes increasing both depend on the smooth factor optimization problem. As a result, this paper optimizes the smoothing factor of GRNN by adaptive PSO algorithm, and the forecasting model is built based on PSO-GRNN. Model algorithm steps are shown in Fig. (3).

The relationship between torque, current and rotor position angle of SRM is highly nonlinear, and the winding current usually is the regular flat wave, so the large torque ripple is inevitable. The literature [15] pointed out that inverse function-i $(T, \theta)$ of SRM can carry out by torque angle characteristic, then use the desired torque inverse model to solve the desired current, finally make the phase current better follow the desired current by corresponding control. But in the process of the inverse function solution, literature [15] used the linear model of SRM and ignored the saturation.

In this paper, the more precise characteristics of SRM is carried out by finite element analysis (FEA), in order to get the torque current angle curve (T-i- $\theta)$, we use magnetic coenergy equation to calculate the corresponding phase torque, 


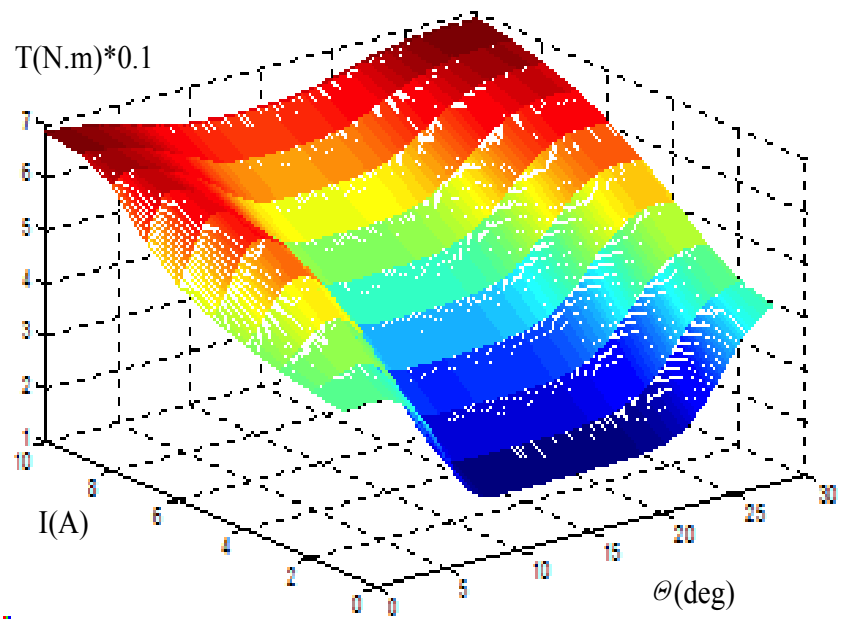

Fig. (4). The torque inverse model of SR motor based on PSO-GRNN.

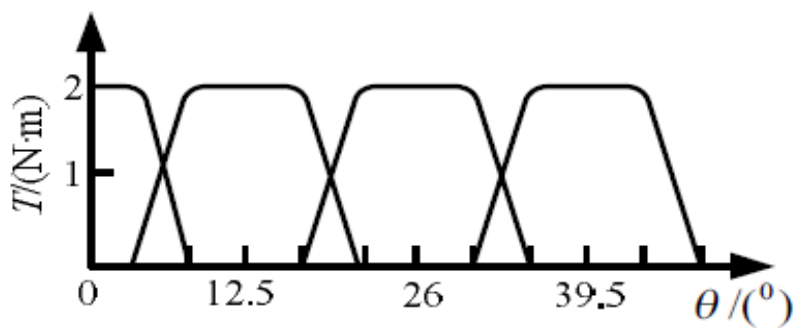

Fig. (5). The cosine TSF.

and this method is on the condition that the perspective ( $\psi-i-$ $\theta$ ) curve reflected fluxlinkage and saturation characteristics has been analyzed by FEA. And through the joint simulation, current waveform is obtained corresponding to the reference torque under different speed, then using GRNN to learn torque angle characteristic of SRM, the input of GRNN is torque $\mathrm{T}$ and rotor angle, and output is given current. since the smoothing factor has great influence on the output accuracy of the network, so use PSO to optimize smooth factor algorithm as shown in Fig. (3), and get the torque inverse model as shown in Fig. (4), it is shown that the smooth factor by PSO optimization is more accurately while training the inverse torque model, and the optimal torque inverse model is more close to the actual motor.

\subsection{The Instantaneous Torque Control System of SRM based on Single-phase Excitation}

As shown in Fig. (2), the instantaneous torque control system includes three sub-modular components: torque sharing function (TSF) design, the torque inverse model solution and the current controller design. The second one has already obtained, so the following work is the other two sub-module design and how to complete the overall modeling system.

\subsubsection{TSF Design}

The role of TSF as shown in Fig. (5) is using the rotor position angle and the total desired torque, assigning the desired torque to each phase reasonably and producing the desired phase torque. As the torque distribution is performed in real time according to the angle, it can avoid commutation torque smooth between phases transition, while the problem of excessive current in single-phase excitation can be solved, and at the same time the torque ripple can be reduced. Note that TSF design also affects the loss and back EMF of the motor.

For $8 / 6 \mathrm{SRM}$, the cycle of TSF is $60^{\circ}$, and the following two basic conditions must be met: The sum of all phases distribution function is equal to 1 ; and the actual phase current should track the expectations current commendably. This paper selects cosine function with rising and falling edges as TSF, and the formula is shown in (3):

$$
f_{j}(\theta)=\left\{\begin{array}{lc}
0.5-0.5 \cos m N_{r}\left(\theta-\theta_{0}\right) & \theta_{0 j} \leq \theta \leq \theta_{1 j} \\
1 & \theta_{1 j} \leq \theta \leq \theta_{2 j} \\
0.5+0.5 \cos m N_{r}\left(\theta-\theta_{2}\right) & \theta_{2 j} \leq \theta \leq \theta_{3 j} \\
0 & \text { others }
\end{array}\right.
$$

In formula (1), $f_{j}(\theta)$ means torque distribution function relative to the phase $j(j=1,2,3,4), \theta_{0 j}$ is the opening angle of phase $j, \theta_{l j}$ the rotor position angle of phase $j$ where the torque stop increasing, $\theta_{2 j}$ is the turn-off angle of phase $j, \theta_{3 j}$ is the rotor position angle of phase $j$ where the torque reduced to zero. The torque distribution function describes the three opened intervals of each phase winding:

1) $\theta_{0 j}<\theta<\theta_{1 j}$ : the torque of opening phase is gradually increased in accordance with the TSF, but the variation rule of turn-off phase is in contrast, the total torque is the sum of the two-phase torque, and the expression is $T_{\text {total }}$.

2) $\theta_{l j}<\theta<\theta_{2 j}$ : the output torque is only separate opening phase, expressed as $T_{\text {total }}$. 


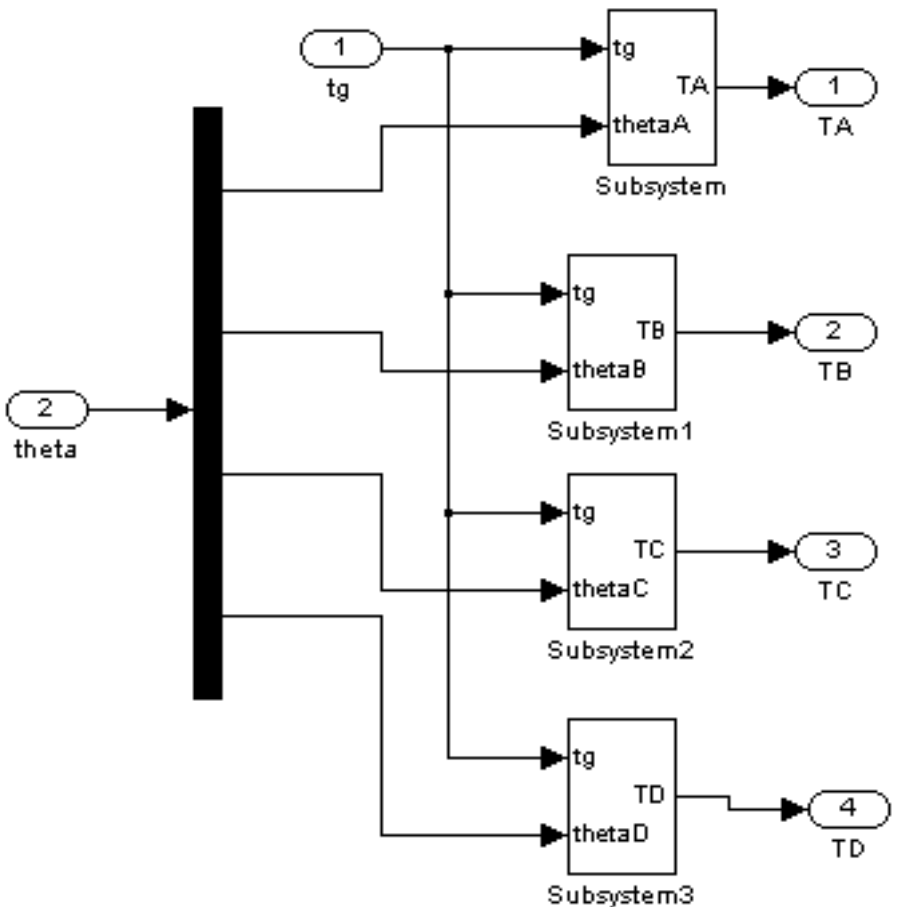

Fig. (6). The torque distribution module.

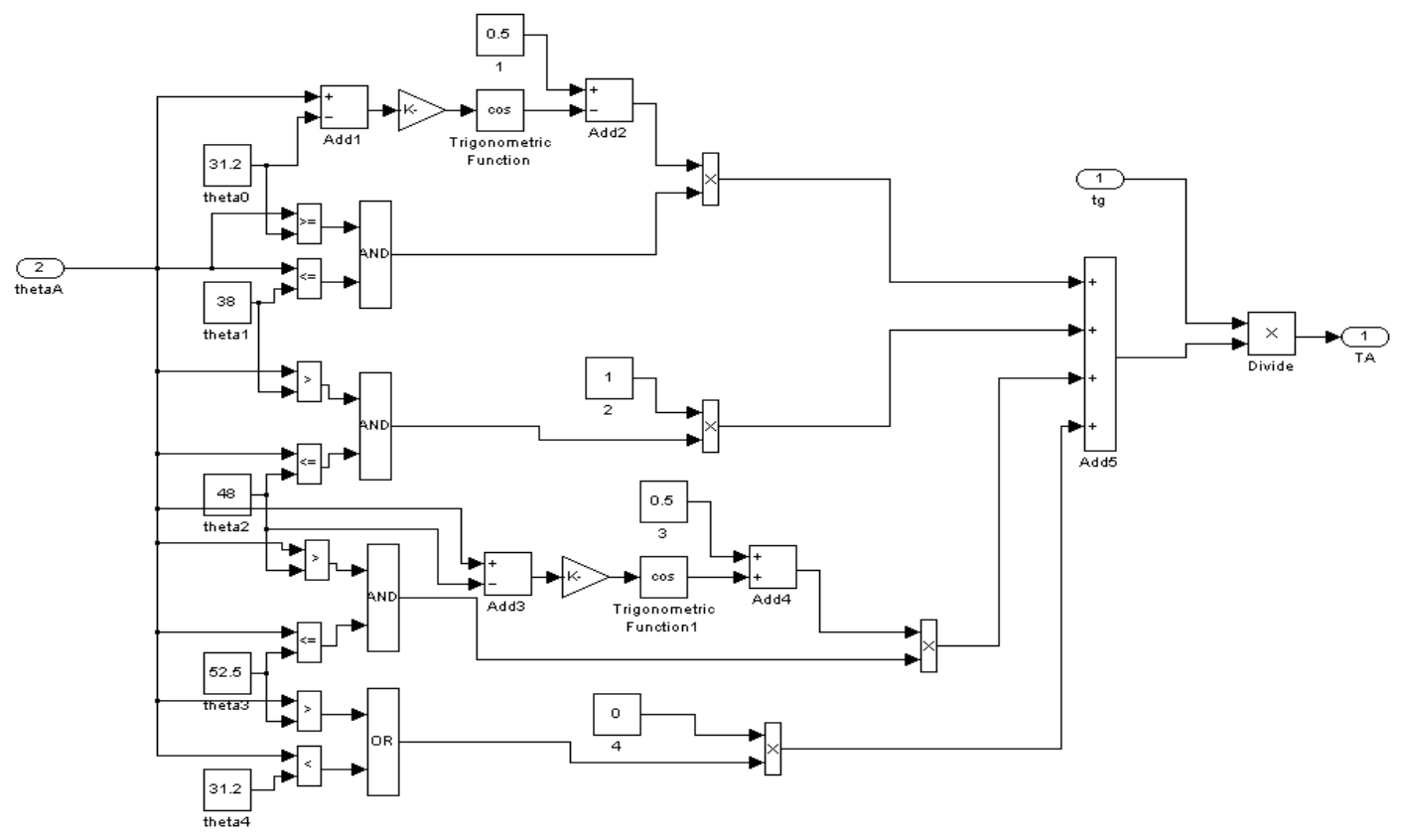

Fig. (7). The realization of cosine TSF.

3) $\theta_{2 j}<\theta<\theta_{3 j}$ : This stage is similar to the first stage, the expression of desired torque phase $j$ is: $T_{\text {ref }}(\theta)=T_{\text {total }} * f_{j}(\theta)$.

TSF can be adjusted the four angles to suit the purpose desired torque, for a four-phase $8 / 6 \mathrm{SRM}$, the values of $\theta_{01}$ to $\theta_{31}$ are $3.5^{\circ}, 8^{\circ}, 17^{\circ}, 21.5^{\circ}$.

\subsubsection{The Simulation Realization of Instantaneous Torque Control Based on Matlab/Simulink}

This paper use Simulink to achieve instantaneous torque control system simulation for SRM, in which the speed regu- lator with PI, TSF, the torque inverse model and current control modules are all built using a modular form.

(1) TSF:

The module input is $T_{\text {ref }}$ and theta, the output is torque distribution of four phase values, the torque distribution module and the cosine TSF respectively are shown in Fig. (6) and Fig. (7).

(2) the torque inverse model:

This module uses lookup table to input PSO-GRNN trained model, and the input variables for lookup table are 


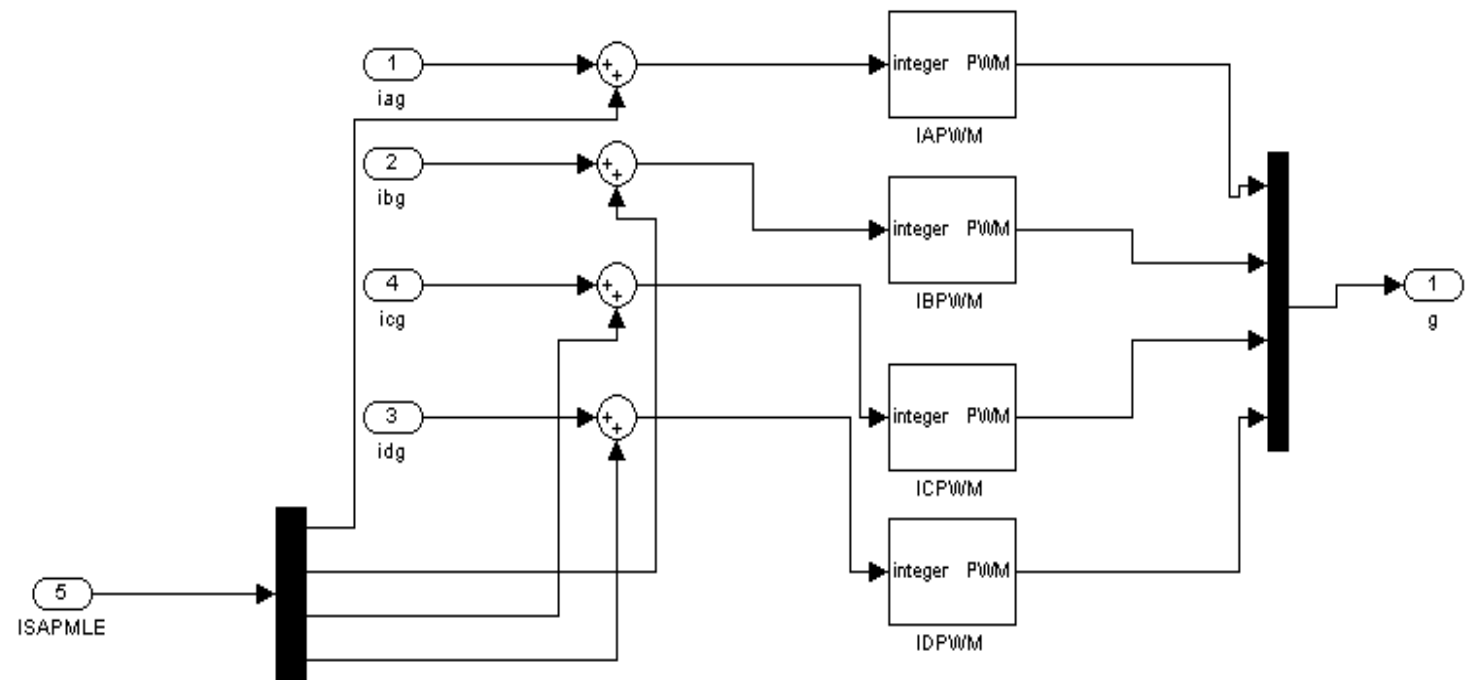

Fig. (8). The current control module.

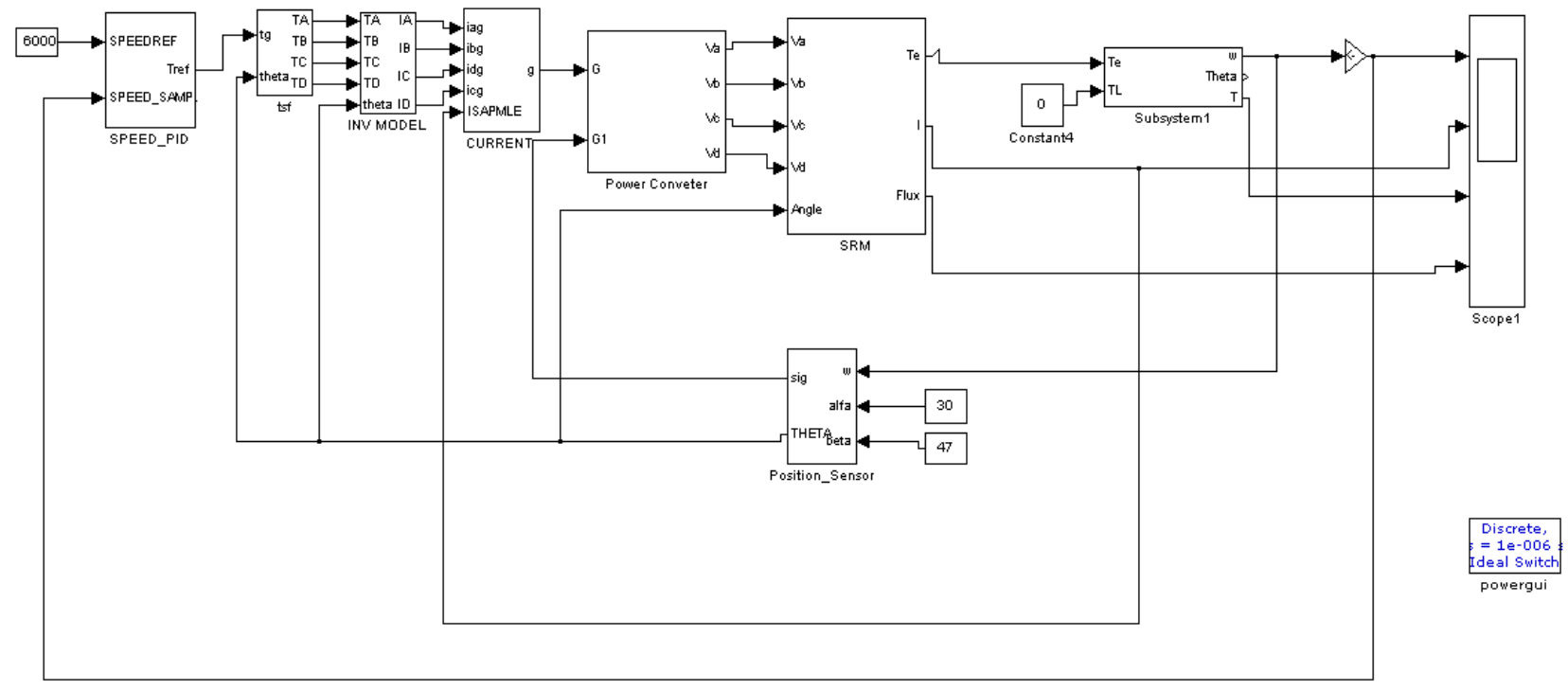

Fig. (9). The instantaneous torque control system of SR motor with inverse model based on PSO-GRNN.

the rotor position and corresponding torque, and the angle of four phase torque inverse model is sequence difference $15^{\circ}$, the output variable is the current value of the nonlinear mapping.

(3) the current control module:

The module input were given current $I_{g}$ and sample current $I_{S A M P L E}$, and the output is in the form of PWM chopper signal, the difference value between given and sample current is the input signal of the PWM generating unit for each phase. During the phase windings conducing, voltage PWM control makes the power switch according to pulse width modulation, let pulse duration $T$ be constant, by the error between the given and the actual speed, regulating the duty ratio to achieve average winding voltage regulation, so as to control the winding current, finally realize the motor speed and torque control.The current control module is shown in Fig. (8).
(4) the overall system simulation model:

On the basis of each single function module, according to the construction principle shown in Fig. (2), the instantaneous torque control system of SRM with single-phase excitation mode is completed as shown in Fig. (9). At the same time, voltage PWM control of the traditional simulation has been made for specific prototype.

The contrast analysis shows in Fig. (10) (a) and (b), compared with the traditional PWM control strategy, the instantaneous torque control strategy has not only reduced the starting current, but also increased the starting torque, and the torque output becomes more smooth, the torque fluctuation is reduced to $0.15 \mathrm{~N} \cdot \mathrm{m}$ approximately, while maximum value of torque fluctuation with the traditional PWM control is $0.4 \mathrm{~N} \cdot \mathrm{m}$, even in the steady-state operation, the torque ripple is $0.2 \mathrm{~N} \cdot \mathrm{m}$. Therefore, the instantaneous torque 


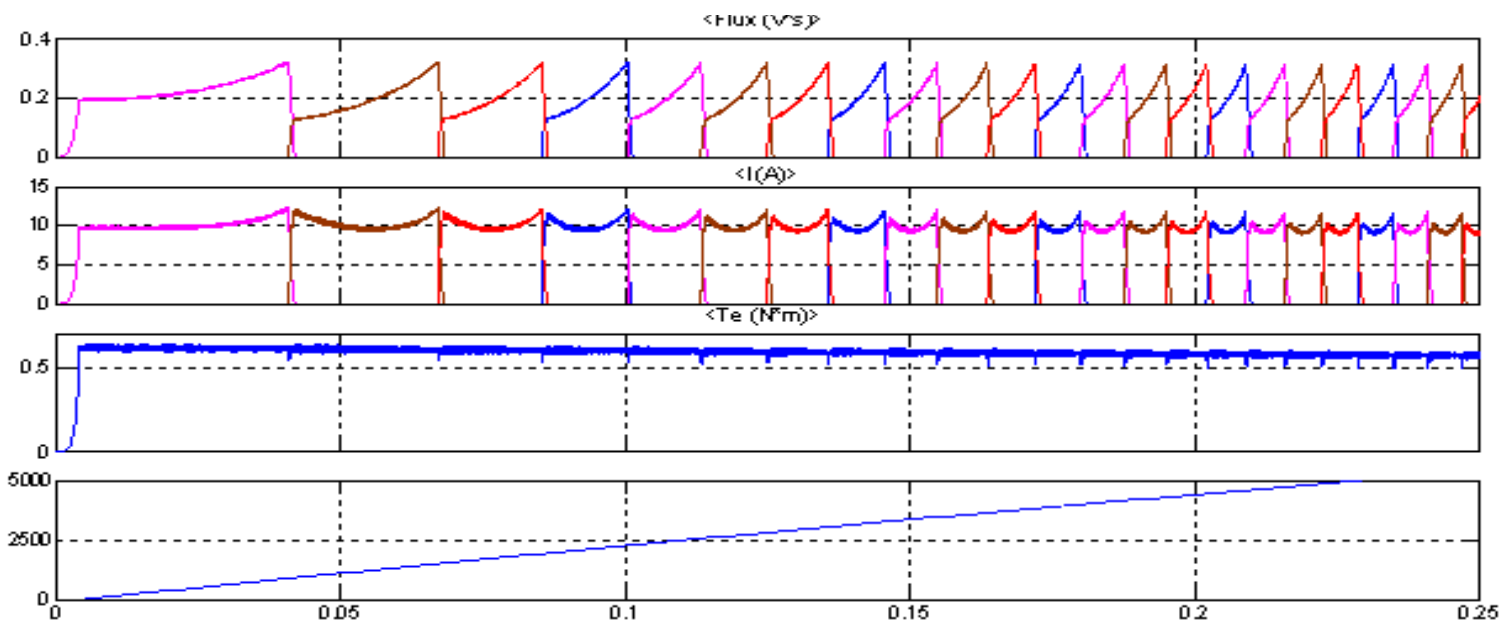

(a) The traditional PWM control strategy
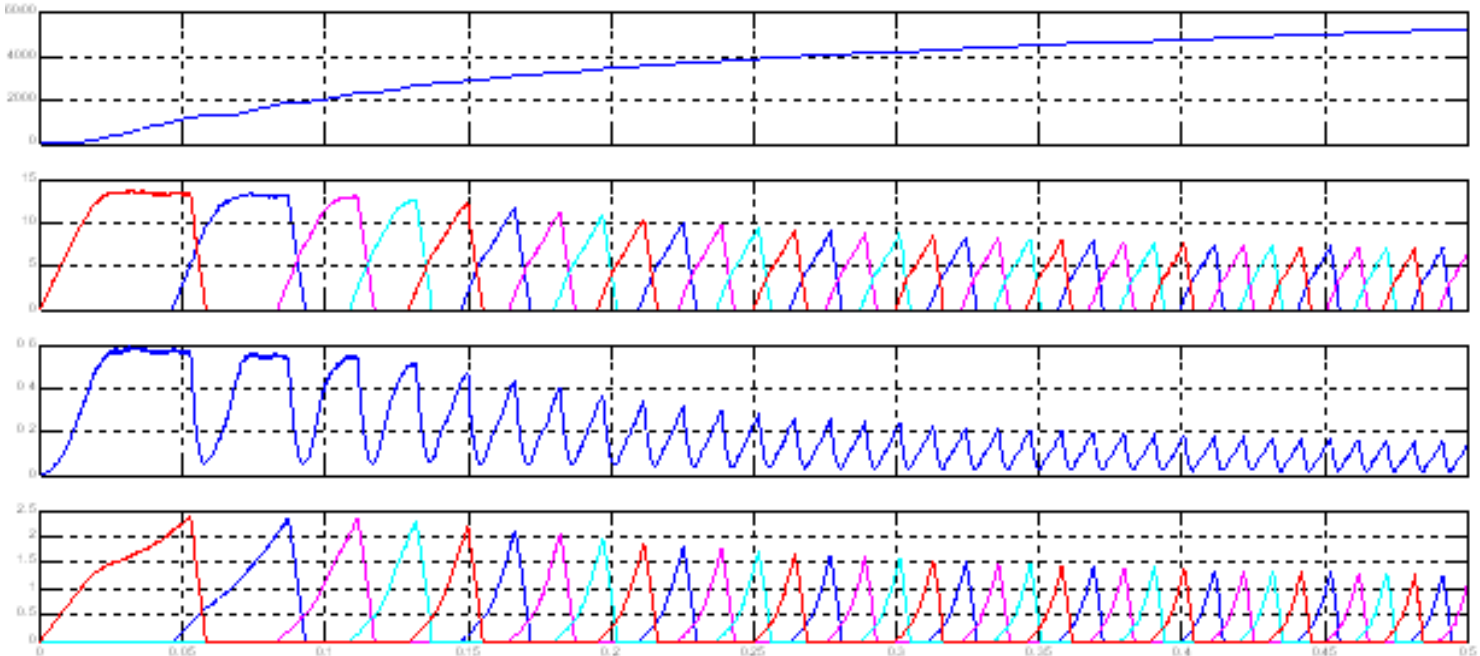

(b) The instantaneous torque control strategy

Fig. (10). The synthesis torque comparison between the instantaneous torque control based on PSO-GRNN and ordinary single phase excitation control

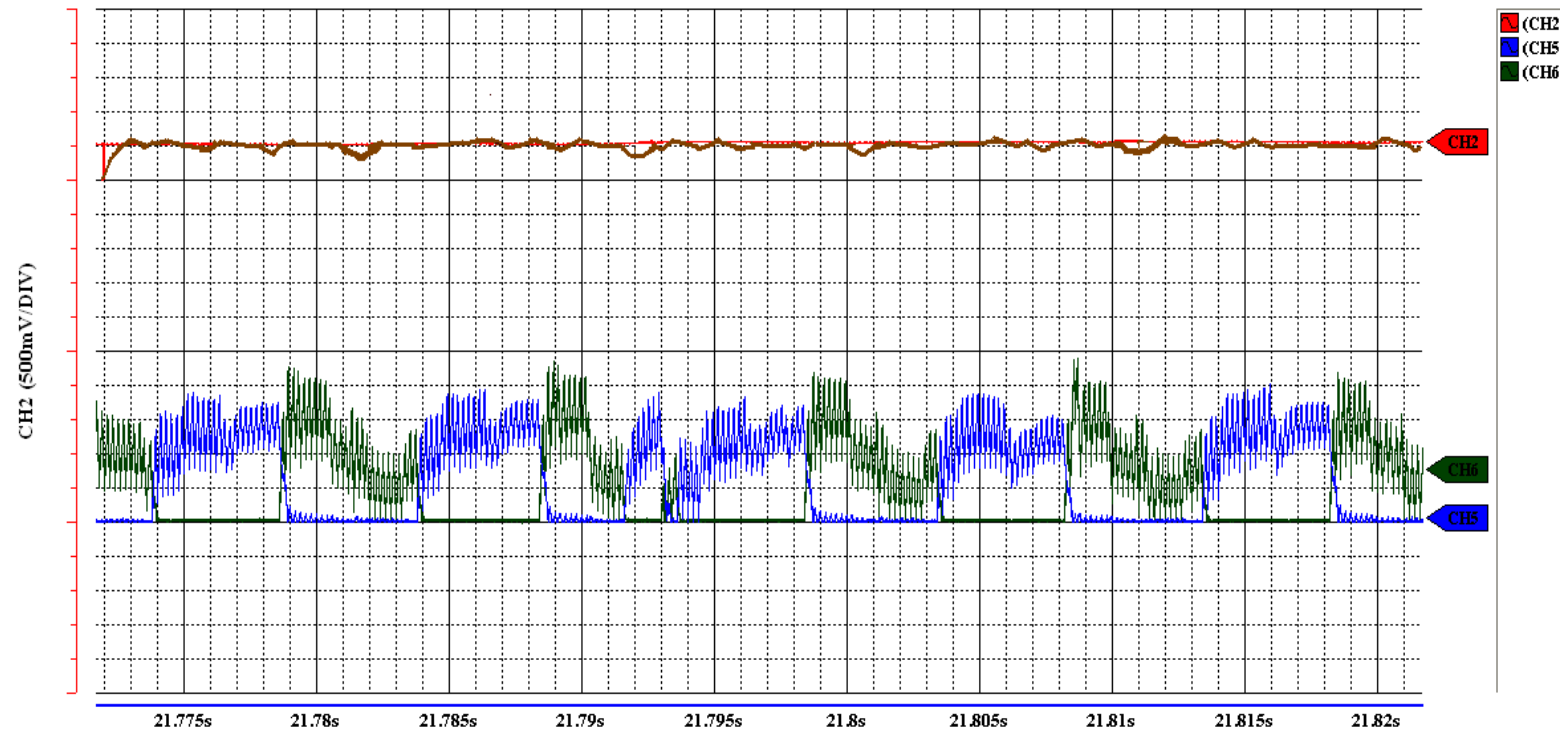

(a) The traditional PWM control strategy 


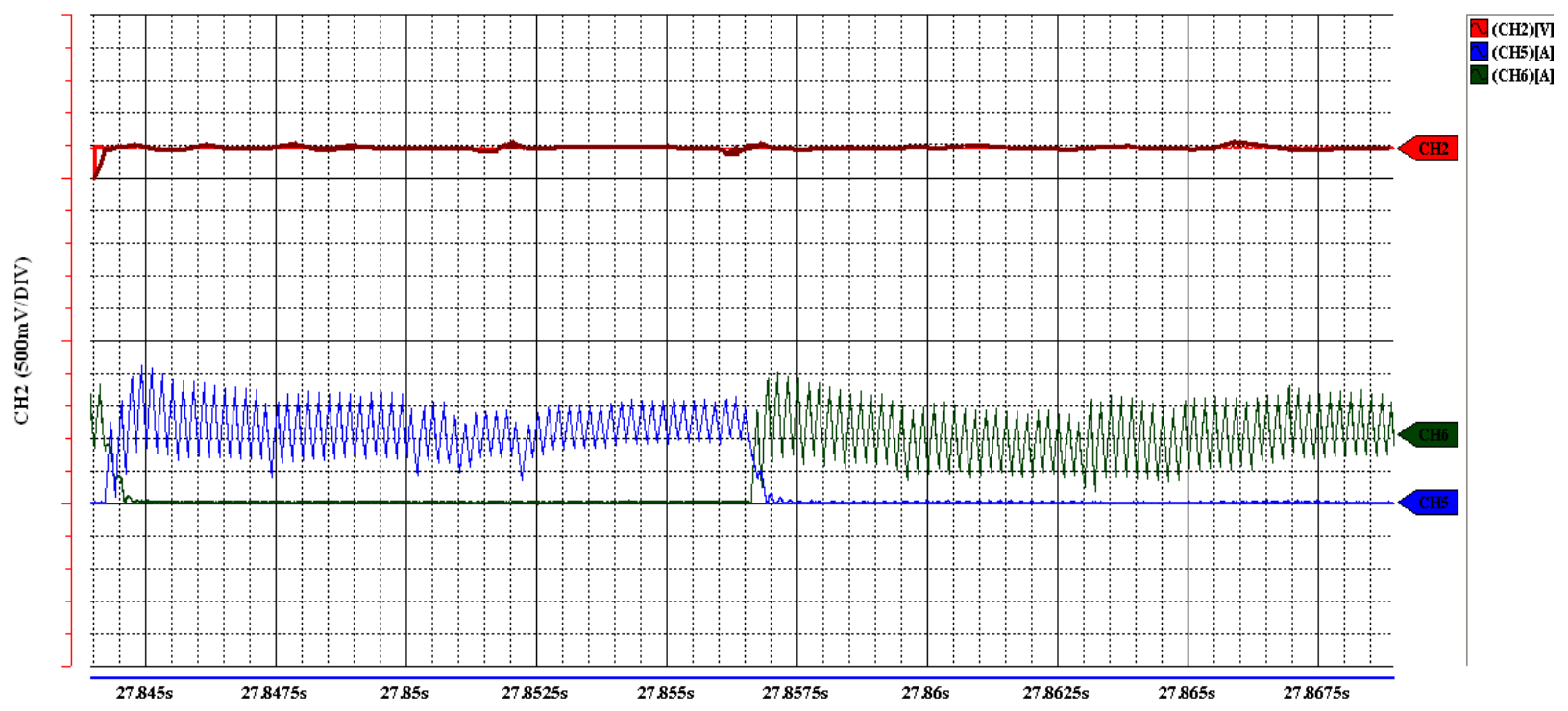

(b) The instantaneous torque control strategy

Fig. (11). Experimental waveform comparison.

control strategy can make the actual current effectively track the given current instruction, and reduce the torque ripple.

\section{EXPERIMENTAL RESULTS}

Further experiments are carried out to validate the control strategy, using TMS320LF2407 as the main controller, the function of speed regulation, the neural network arithmetic are based on DSP programming, synthetic torque waveform of the same prototype in the conventional control and instantaneous torque control under steady state operation as shown in Fig. (11). Through the comparison we can see, at the same speed, in the conventional control mode, the phase current fluctuations with large torque ripple, especially in the commutation conduction, the torque ripple can be achieved $0.2 \mathrm{~N} \cdot \mathrm{m}$, and instantaneous torque control directly based on the synthesis torque, using torque inverse model to calculate the phase current to follow the current given, finally achieve good torque control results, the amplitude of torque ripple is less than $0.1 \mathrm{~N} \cdot \mathrm{m}$, at the same time, the instantaneous torque control can adapt to the current changes caused by speed, and current fluctuation is reduced and the system is more robust.

\section{CONCLUSION}

This paper analyzes electromechanical actuator technology of all electrical braking system, Taking the reliability and redundancy into account, the SRM is selected to be the optimization scheme of this paper, the working principle and control method of SRM which is the core of electromechanical actuator is described, in view of the characteristics of the all electrical braking system and the Inherent defects of SRM, using PSO-GRNN to build instantaneous torque control system so as to inhibiting torque ripple, this paper uses software MATLAB/ SIMULINK tools and experiments to study on all electrical brake system based on instantaneous torque control of SRM, results show that: the system has a good dynamic performance, can quickly and accurately track the desired braking system.

\section{CONFLICT OF INTEREST}

The author confirms that this article content has no conflict of interest.

\section{ACKNOWLEDGEMENTS}

This work was supported by the basic scientific research business expenses of central special universities (3122013D018), and scientific research foundation (2013QD02S), which are both belong to Civil Aviation University of China.

\section{REFERENCES}

[1] J. A. Rosero, J. A. Ortega, E. Aldabas, L. Romeral, "Moving towards a more electric aircraft," Aerospace Electron. Syst. Mag., IEEE, vol. 22, no. 3, pp. 3-9, 2007

[2] H. Klode, A. M. Omekanda, B. Lequesne, S. Gopalakrishnan, A. Khalil, S. Underwood, I. Husain, "The potential of switched reluctance motor technology for electro-mechanical brake applications", In: Proceed. SAE World Cong., Detroit, MI, 2006, pp. 01-02.

[3] A. Emadi, S. M. Lukic, F. Rodriguez, "Digital control of motor drives", U.S. Patent 7960931. Jun 14, 2011.

[4] R. Krishnan, "Switched reluctance motor drives modeling, simulation, analysis, design and applications", London: CRC Press, 2001.

[5] F. Sahin, H. B. Ertan, K. Leblebicioglu, "Optimum geometry for torque ripple minimization of switched reluctance motors", IEEE Trans. Energy Conver., vol. 15, no. 1, pp. 30-39, 2000.

[6] T. Wichert, "Design construction modifications of switched reluctance machines," Warsaw University of Technology, 2008.

[7] K. Vijayakumar, R. Karthikeyan, S. Paramasivam, R. Arumugam, K. N. Srinivas, "Switched reluctance motor modeling, design, simulation, and analysis: A comprehensive review", IEEE Trans. Magnet., vol. 44, no. 12, pp. 4605-4617, 2008. 
[8] K. T. Hung, T. A. Lipo, R. D. Lorenz, J. C. Moreira "Motor torque control method and apparatus", U.S. Patent 5334923. Aug 02, 1994.

[9] R. Mitra, W. Uddin, Y. Sozer, I. Husain, "Torque ripple minimization of Switched Reluctance Motors using speed signal based phase current profiling”, In: Energy Tech. 2013 IEEE. pp. 1-5, 2013.

[10] J. Ahn, D. H. Lee, "Torque control method for high-speed switched reluctance motor", U.S. Patent 8441223. 2013-5-14.

[11] B. Fahimi, U. Krishnamurthy, "Techniques and apparatus for the measurement of mutual inductance in a switched reluctance machine", U.S. Patent 8,125,170. Feb 08, 2012-2-28.
[12] H. Ishikawa, Y. Kamada, H. Naitoh, "Instantaneous current profile control for flat torque of switched reluctance motors", Elect. Eng. Jpn., vol. 163, no. 3, pp. 65-69, 2008.

[13] A. C. Koenig, "Torque harmonic reduction control for switched reluctance machines", U.S. Patent 8080969. 2011-12-20.

[14] L. Bo, Y. Li, "Research on simulation of aircraft electric braking system", Recent Adv. Comput. Sci. Inform. Eng. 2012, pp. 301-309.

[15] W. Cox, "Method for reducing requirements for aircraft brake size, complexity, and heat dissipation", U.S. Patent Application 13/543,768. Jul 06, 2012.

Received: September 22, 2014

(C) Bing and Jie; Licensee Bentham Open.

This is an open access article licensed under the terms of the Creative Commons Attribution Non-Commercial License (http://creativecommons.org/licenses/by-nc/3.0/) which permits unrestricted, non-commercial use, distribution and reproduction in any medium, provided the work is properly cited. 